\title{
Understanding Fayalite Chemistry using Electron Microscopy and Atom Probe Tomography
}

\author{
B.W. Arey, D.E. Perea, L. Kovarik, R.J. Colby, J. Liu, O. Qafoku, A. R. Felmy \\ Pacific Northwest National Laboratory, Environmental Molecular Sciences Laboratory, Richland, WA, \\ USA
}

Olivines, a significant constituent of basaltic rocks, have the potential to immobilize permanently $\mathrm{CO}_{2}$ after it is injected in the deep subsurface, due to carbonation reactions occurring between $\mathrm{CO}_{2}$ and the host rock. However, the extent of mineral carbonation reactions is dependent upon the spatial distribution of the chemical components within the mineral. Fayalite, the iron-rich end member of the olivine series $(\mathrm{Mg}, \mathrm{Fe})_{2} \mathrm{SiO}_{4}$, occurs in abundance in the Earth's upper mantle and it can be a significant constituent of basaltic rocks. The isolated tetrahedral structure of fayalite can breakdown during reaction with aqueous solutions and it is known that the dissolution of fayalite is accelerated if high temperatures, acidic solutions and far from equilibrium conditions are present. During fayalite dissolution its constituents $\left(\mathrm{Fe}^{2+}\right.$ and silica) will be released from the structure and can participate in precipitation reactions with nearby anions to form secondary minerals: (hematite, goethite, sulfites, carbonates, amorphous silica). In this study we will present the new methods for determining the spatial distribution of the light elements $(\mathrm{Na}, \mathrm{Li}$, and $\mathrm{Ca})$ within the mineral fayalite. These elements may play a role in carbonation reactions of fayalite under super critical $\mathrm{CO}_{2}$ conditions.

We will show different techniques and how each one is has it strength and weakness in detecting light elements, Scanning Electron Microscopy Energy Dispersion Spectroscopy (SEM-EDS), The EDS spectrometer is especially useful for qualitative analysis because a complete spectrum can be obtained very quickly. The energy-dispersive $\mathrm{x}$-ray spectrometer is an attractive tool for qualitative $\mathrm{x}$-ray microanalysis.

Electron Microprobe (EMPA), Quantitative EPMA analysis is the most commonly used method for chemical analysis of geological materials at small scales. An electron probe is the primary tool for chemical analysis of solid materials at small spatial scales (as small as 1-2 micron diameter); hence, the user can analyze even minute single phases (e.g., minerals) in a material (e.g., rock) with "spot" analyses.

High Resolution Scanning Transmission Electron Microscopy (STEM), a highly-focused electron probe is raster-scanned across the material, and various types of scattering are collected as a function of position. The transmitted electrons at high scattering angle can be collected to form high-resolution, chemically sensitive, atomic number (Z-) contrast images. The X-rays generated can be collected using an energy-dispersive X-ray spectroscopy (EDS) detector and used to form high spatial resolution compositional maps. Electron energy losses can be detected using a Gatan image filter (GIF) to map the compositional and electronic properties of materials.

Atom Probe Spectroscopy (APT), is a state-of-the-art analytical method that allows for threedimensional elemental mapping with near atomic resolution. It is a powerful tool that can provide 
unique compositional information on a variety of materials systems such as complex alloys, semiconductor materials and devices, and ceramic material [1].

\section{References:}

[1] This work was supported by the U. S. Department of Energy (DOE), Office of Basic Energy Sciences through a Single Investigator Small Group Research (SISGR) grant at Pacific Northwest National Laboratory (PNNL). This research was performed using EMSL, a national scientific user facility sponsored by the Department of Energy's Office of Biological and Environmental Research located at Pacific Northwest National Laboratory.

PNNL is operated for DOE by Battelle Memorial Institute under Contract\# DE-AC05-76RL0-1830.

Mass spectrum analysis of Unreacted Natural Fayalite

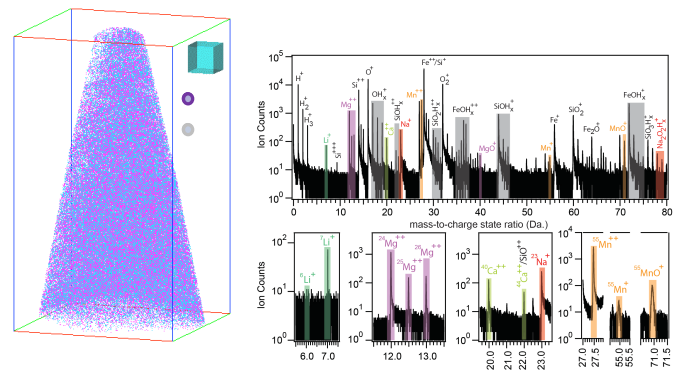

$3 \mathrm{D}$ reconstruction map $5 \%$ of $\mathrm{Fe}, \mathrm{Si}$ and $\mathrm{O}$ are displaced for clarity

Figure 1. Atom Probe data from natural fayalite mineral

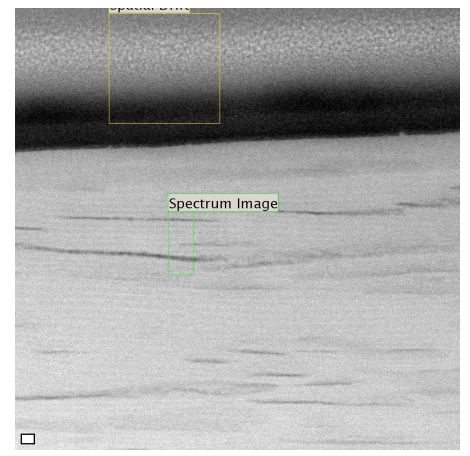

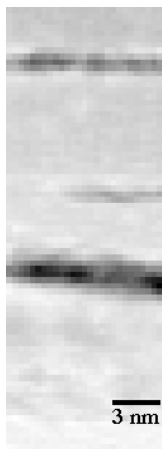

ADF

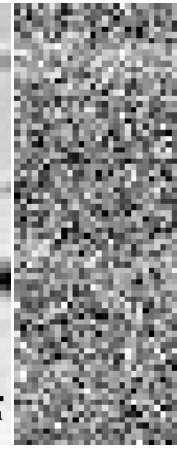

$$
\begin{aligned}
& \text { O K } \\
& \text { pre - } \\
& \text { peak }
\end{aligned}
$$

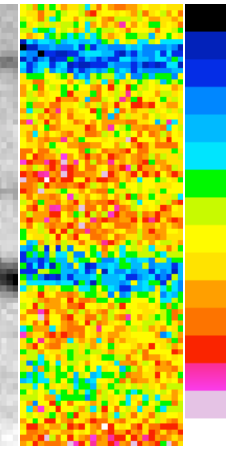

711.4

710.

709.

Figure 2. TEM image with EELS composition data 